\title{
Avoiding Cultural Imperialism in the Human Right to Health
}

\author{
Kathryn Muyskens ${ }^{1}$
}

Received: 8 June 2021 / Revised: 7 September 2021 / Accepted: 7 September 2021 /

Published online: 19 October 2021

(c) National University of Singapore and Springer Nature Singapore Pte Ltd. 2021

\begin{abstract}
As political instruments, human rights can be challenged in two important ways: first, by undermining the claim to universality by appealing to a kind of cultural relativism, and second, by accusing human rights of unjustifiably imposing values that are not genuinely universal (which I dub the problem of parochialism). The human right to health is no exception. If a human right to health is to be a useful instrument in mobilizing action for global health justice, then we need to take seriously the ways that health intersects with culture. Universal applicability is essential to both the legitimacy and efficacy of human rights. But without cultural sensitivity, additional injustices and imperialistic harms may be perpetuated. There are two goals within this paper-(1) to show that cultural imperialism is a moral and practical hazard, both in general and for the human right to health in particular and (2) to articulate a way of thinking about the human right to health that can minimize these hazards and arm it with moral credibility and political weight.
\end{abstract}

Keywords Human rights · Right to health - Cultural imperialism · Global health · Public health ethics

\section{Introduction}

Human rights are nothing if not controversial and the human right to health perhaps more so than most. Though they have gained increasing acceptance in the international discourse, generating numerous international agreements like the Universal Declaration of Human Rights (UDHR) and the International Covenant on Economic, Social and Cultural Rights (ICESCR), there is still much disagreement at the theoretical level over what it means to claim that something is a human right. Within the philosophical literature, debate continues over what is known as the "grounding problem" (see

Kathryn Muyskens

yncklm@nus.edu.sg; klmuyskens@gmail.com

1 Yale-NUS College, Singapore 
Cruft et al. 2015) and with regard to which rights deserve the status of a human right (see Talbott 2005). At the same time, there is still resistance by some groups against accepting the idea that human rights exist at all. Though there are many possible critiques of human rights, in this paper I will address the objections that come from two prominent fronts (1) the cynical accusation that human rights are merely excuses for Western countries to justify intervening in the affairs of other states that do not share the same values (i.e., the problem of imperialism) and (2) relativistic worries that it is neither true nor fair to claim that one set of cultural values is superior to another, and therefore no universal standard is possible or justified.

Often, it is the Western liberal norms (especially those regarding individualism and personal autonomy) supposedly embedded in human rights discourse which draw the most fire from those concerned with cultural imperialism (defined as the creation and maintenance of unequal relationships between cultures in a way that unfairly privileges the more powerful society). The famous "Asian Values" debate was one such case-where a variety of Asian nations pushed back on universal human rights because its liberal presuppositions were perceived to be in conflict with the communitarian roots of Asian societies (see Nie 2005, Dallmayr 2002, Gawlikowski 2000, and Li 1999 for more discussion of this debate). The human right to health more often draws a different kind of criticism, i.e., concerns that it is vague (Nozick 1974), impractical, or infeasible (Sreenivasan 2012) or criticisms about the validity (or lack thereof) of so-called "positive rights" (Goodman 2005). The worry about ethnocentric or parochial bias (e.g., the assumption that one's own cultural views and norms are universal and objective) is less commonly directed at the human right to health, since many wrongly assume that health is a clear and universal term. However, ignoring cultural differences in a right to health runs just as much risk for unjust impositions as in the context of other human rights.

Parochial bias, and the cultural imperialism it can fuel, is a moral hazard that any human rights activist should take very seriously. If we cannot work successfully across cultures, coordinating the kinds of actions needed to effectively address global health problems - like famine, infectious disease, climate change, etc.- -will be impaired, and this impairment will mean that lives are shortened and lost. Thus, in this paper, I aim to make clear that we have reason to use the language of human rights to protect and improve global health while at the same time acknowledging the concerns for cultural sensitivity. Accordingly, I will focus on two goals within this paper-(1) to show that cultural imperialism is a moral and practical hazard, both for human rights in general and for the human right to health in particular, and (2) to articulate a way of thinking about the human right to health that can minimize these hazards and arm it with moral credibility and political weight.

\section{Human Rights as Instruments against Injustice}

\section{What are Rights?}

Whatever else they may be, human rights are a species of right. So, before moving forward with the present discussion, it is useful to say a little about the nature and purpose of rights in general - with the aim of making it clear why it is important to salvage human 
rights' potential as political instruments instead of giving up on rights-based discourse as hopelessly parochial. Broadly, rights can be either legal or moral. Legal rights are rights that states grant their citizens through law or custom. In contrast, moral rights are not dependent on the state's recognition. Moral rights, sometimes called natural rights, are thought to be grounded in human nature or to be endowed by divine law.

Modern theories of what grounds rights typically break down into two camps: the will theory and the interest theory (Kramer 2013). Under the will theory, rights protect the choices of the right holder and preserve the person's ability to make choices. A good example is the practice of informed consent in medicine, which protects the patient's right to decide what treatments he or she will accept or reject. On the interest account, rights protect the interests of the right holder (interests being what furthers the subject's wellbeing), regardless of the individual's ability to make choices. For example, if someone pulls a person out of the way of an oncoming car, they are acting in that person's interests, regardless of whether that person gave consent to being grabbed. In most scenarios these two theories converge, because people tend to choose what is in their interests.

A right not to be assaulted both protects the person's well-being and ability to make choices. But the will theory gives some decidedly counterintuitive answers in other cases. For instance, under the will theory of rights, anyone with diminished reasoning capacity, like the very elderly, disabled, or even children, might be excluded from the community of rights-holders since they do not have the same ability to reason and make choices. The interest theory is more inclusive but presents another problem. How can we demarcate the community of right holders? Anything that is alive can be said to have interests in this way: animals have an interest in not being hunted, and grass has an interest in not being cut. But how can we decide which interests should be protected with rights? The will theory is clearly too narrow, but the interest theory may be too broad. Ultimately, the truth is likely somewhere in between these two views. Rights serve to protect us against coercion and enshrine respect for the choices we make, but this protection ought also to extend to our interests (regardless of whether they align with conscious choice).

\section{What are Human Rights?}

When it comes to human rights, there are echoes of similar conceptual divides: moral vs legal, will vs interest, etc. Just to name a few, there is the "agency account" defended by Griffin (2008), the "interest account" popularized by Tasioulas (2007), and the "political conception" defended by philosophers like Beitz (2009) and Raz (2010). Some definitions of human rights are conceptually "thicker" than others (particularly those which rely upon an atomized concept of the individual-a hallmark of Western values) - and thus less easily translatable to other cultures and contexts. Of course, historically speaking, rights-based discourse itself is Western in origin-so it might seem hopeless or absurd to hope for a completely neutral culture-free conception of human rights. Yet, merely having an origin in one particular cultural context need not invalidate a claim to universality. Truth is truth no matter who finds it first-as we readily accept with discoveries made in science or mathematics. 
While these arguments about the moral and conceptual grounding of human rights have their place, in this paper, I am more concerned with the way that human rights (and specifically the human right to health) is put into practice as a political instrument-meaning, the way that human rights language is employed to justify international criticism and interventions on behalf of health and wellbeing. This aligns my view more strongly with that of Wolff (2012), Raz (2010), and Beitz (2009), who define human rights by their function in the international political realm-where they serve as a source of political legitimacy when they are respected and as triggers or justifications for intervention when they are violated. In some sense, this political view bypasses the grounding question by remaining agnostic about the theoretical underpinnings or remaining open to pluralism in that regard. From there, the discussion can move on to other questions about which rights are human rights and what they demand in practice.

Whether we think they are legal or moral in nature, grounded in will or interests, rights are invoked for particular functions in societies. When we invoke rights, we may validly do so in the name of our interests and our choices. At the same time, it only makes sense to appeal to "rights" if we have political institutions to which we can address the claims and a reasonable expectation that doing so will have any effect.

Even if we might disagree about their fundamental nature, we must admit that we use rights-based discourse primarily (although perhaps not exclusively) in the political realm, to defend the individual from the powers of the society and state (Wolf 2012, 15-16). We do not usually invoke our rights in intimate relationships or when our interests are thwarted by natural phenomena. As the political philosopher Jonathan Wolff (2012) has put it, human rights have a double role-(1) as a statement of the minimum moral obligations owed to every human and (2) as a mechanism of accountability beyond the nation-state.

\section{Are Human Rights Universal?}

In this function as political instruments, however, human rights can be undermined in two important ways: first, by undermining the claim to universality by appealing to a kind of cultural relativism, and second, by accusing human rights of unjustifiably imposing values that are not actually universal but instead peculiar to a particular culture or time. Both objections focus on the claim to universality of human rights, the first arguing that there can be no such thing and the second arguing that human rights, as stated or practiced, have missed the mark. Successfully avoiding these accusations is like navigating through Scylla and Charybdis. As political instruments, universal applicability is essential to both the moral legitimacy and efficacy of human rights. The accusation of parochial bias, however, is undermined by the fact that many non-Western nations played an active role in the formation of international human rights agreements. Indeed, in the initial creation of international documents, like the UDHR and ICESCR, the concerns of less powerful nations and their peoples were brought to the fore, thanks to "intensive lobbying by Carlos Romulo of the Philippines, Herbert Evatt of Australia, and philosophy professor Charles Malik 
of the Lebanese Republic, together with several Latin American states" (Wolff 2012, 3-4). Thus, even if human rights are not universal in the sense of being unanimously accepted in the realm of international politics, the origin of these international documents give us reason to believe the human rights they describe do in fact represent a set of common and shared values, not merely values peculiar to the West.

\section{The Rock and The Hard Place: Parochialism and Relativism}

\section{The Perils of Parochialism}

Why is it important to avoid cultural parochialism in human rights in the first place? Those who doubt that parochialism is a problem might wonder: if one culture hits upon something that is truly good, what could be wrong about exporting that to other cultures? After all, isn't that what happens with almost everything we enjoy? Do we want to claim that it was wrong for the first people that discovered mathematics to teach it to their neighbors? Certainly not. It is a very human trait to mimic what we like in others and recreate it for ourselves. Good ideas (and sometimes even bad ones) are contagious. Those who reject the legitimacy of human rights because of perceived parochialism are not upset because the ideas have an origin in one place as opposed to another, but because they perceive something coercive is at work. Indeed, the playing field of international politics is not equal. While the days of the old colonial empires are largely gone, the globe is still dealing with the aftermath. This continuing power imbalance makes coercion possible, even in situations where it is not intended, since, as Thomas Pogge $(2002,367)$ puts it, "the better off are able to impose a shared institutional order on the worse off'. When this power imbalance gives over to an infringement on the agency of the less powerful group, it becomes imperialism and, in its more subtle forms, cultural imperialism.

The political philosopher, Lisa Fuller (2012), argues that cultural imperialism is still a pressing problem in humanitarian activities today, including those concerning health. While colonial era imperial practices were carried out with the belief that one culture was superior to another, and involved coercive pressures to intentionally alter the beliefs and practices of the so-called "inferiors," Fuller argues that cultural imperialism can be defined by its coercive effects alone (Fuller 2012). The beliefs and intentions of the powerful group matter much less than the effects of the offers they make on the less powerful, and whether they have a realistic option to refuse (Fuller 2012). Parochialism in human rights, and the related potential for cultural imperialism, is problematic - not because of the content of the beliefs it may privilege, but because of this injury to the agency of less powerful people. Interfering with the self-determination of other communities is not only morally suspect, but it undermines the ability of human rights to be effective political instruments against injustice and is thus a practical hazard as well as a moral one. An Archimedean point is not always attainable, but ignoring cultural difference will always be a political non-starter. Ideas have origins, but it is a bad idea to go down the path of rejecting or adopting ideas based on their origins. 
The real question should be how can we ensure the best efforts are being made to avoid parochial bias in our ethical evaluations? We have two options to answer this. We could give up on the idea that different human societies can cooperate successfully and leave each society to fend for itself. However, in the face of global crises (like pandemics, climate change, etc.), we are all made worse off if we simply resign from trying to find common ground. Many of these problems are not possible to handle without global coordinated efforts and cooperation. So, what is the alternative? We must strive to find a language we can all appeal to when faced with these shared problems. Universal human rights are the closest we have to such a language, even if imperfect.

\section{Responding to the Relativists}

Cultural relativism (the belief that moral standards exist if and only if a cultural group holds them to exist, and that these standards apply only within that group) has found popularity in certain disciplines, notably within anthropology. In part, the appeal of this trend may be attributable to a pushback against the era of colonialism and ethnocentrism that produced so much suffering around the world. This is an understandable reaction. Yet, we should not uncritically accept the premise that we must side with the relativists to avoid accusations of ethnocentrism.

The American Anthropological Association (AAA) released two statements in response to the UDHR, one in 1947 and one in 1999. The first statement reflected the widely held belief at the time that human rights and cultural tolerance were somehow at odds. The idea was that the acceptance of conflicting cultural norms and values entailed a rejection of human rights' norms (Engle 2001). The second statement in 1999 was initially seen as a turnaround from the earlier position, as the AAA seemed to back down on the argument that human rights and cultural tolerance were necessarily opposed. Yet, both statements strongly advocate for the protection of culture, sustaining the continued tension between tolerance and judgment (Engle 2001).

The trend of Boasian anthropology, named after its founder Franz Boas, emphasizes the need to understand cultures in their own terms. ${ }^{1}$ Yet, our approval for methodological relativism in the process of anthropological research should not make us uncritically accept the premise that we must side with the relativists to avoid accusations of ethnocentrism in the moral realm.

Cultural relativists claim that "a moral judgment is true just because it describes what a society really stands for" (Shafer-Landau 2018, 300). As Shafer-Landau (2018, 301) describes, this argument reduces moral claims to "veiled reports of cultural commitments"; the implication is then that wherever cultural norms have permitted slavery, genocide, or honor killing, the perpetrators' hands are clean as long as their society backed these actions at the time. Another political philosopher,

\footnotetext{
${ }^{1}$ I should note that cultural relativism is complicated by the fact that cultures are themselves fluid and changing, as well as heterogeneous entities. Determining which values are the "true" values of a particular culture is thus a fraught issue-and one too big to address in this paper.
} 
William Talbott (2005), has made stronger claims against cultural relativism as it relates to human rights. Talbott discusses and debunks several possible defenses of cultural relativism. I will discuss two of them here, (1) the "incommensurability thesis" and (2) the "claim of distorting bias" (Talbott 2005, 45-47).

The "incommensurability thesis" claims that different culture's moral outlooks are fundamentally irreconcilable. Yet, Talbott points out, if the values of other cultures were truly incommensurable, their internal norms would necessarily be opaque to us. Talbott gives the example of Hindu cultural norms as seen by a Westerner. The cultural relativist would claim that Westerner's cannot criticize Hindu customs but then goes into great depth about how the internal norms of Hindu society function. Talbott argues that if these norms can be successfully explained to an outsider, then they are not opaque and thus not incommensurable.

Next, the "claim of distorting bias" argues that we are incapable of separating ourselves from our own cultural contexts and biases and that this prevents us from being impartial in any evaluation of cultures not our own. To this argument, Talbott cedes some ground. Indeed, he says, this is sometimes true-as with the Spanish conquistadors in the Americas (Talbott 2005, 47). Yet, just because it is hard to separate ourselves from our own cultural biases, this does not mean it is impossible. In fact, sometimes an outsider's perspective is necessary to gain clarity about the morality of a culture's internal moral norms. To that end, international human rights can provide a platform for this very kind of cultural criticism-offering all cultures a method of gaining insight into their own parochial biases and a chance to re-evaluate their norms and beliefs.

To develop a system of international human rights, we cannot get very far if we accept that morality is relative. Further, accepting moral realism need not entail privileging one society's views over the views of others. The moral realist simply claims that it is possible for a society to be wrong about what is moral while not being necessarily committed to the belief that any person or society actually has discovered the correct moral code. It's perfectly possible that we are all wrong. Thus, we do not need to be relativists to avoid imperialistic harms; we simply need to admit the possibility that our perspective is limited and fallible.

Together, the arguments from parochialism and relativism raise moral and practical concerns that any human rights advocacy needs to take seriously. Yet, these are hazards which it is possible (even if difficult) to overcome. Furthermore, given the value of this tool (even if imperfect) in our arsenal against injustice, we should be loath to relinquish the use of the language of human rights. In the following section, I will give some examples of the culturally imperialistic value conflicts which emerge in the realm of global health. Then I will suggest some strategies that may allow these problems to be avoided or at least mitigated.

\section{Cultural Imperialism in Global Health}

As mentioned in the introduction, the problem of cultural imperialism is sometimes neglected with regard to the human right to health. It seems that "health" is often (wrongly) assumed to be a value-free and objective term. Even Fuller, who's 
explicit interest in her 2012 paper is in preventing cultural imperialism in humanitarian health interventions, falls prey to this assumption. In an attempt to provide humanitarian workers a way to navigate the complexities of cross-cultural negotiations, she draws a line between the "factual" and "moral" beliefs (Fuller 2012). She then advises that health INGOs avoid attempting to change the "moral" beliefs of the recipients of aid but permits them to educate the recipient communities out of inaccurate "factual" health-related beliefs. Although such a line between the two kinds of beliefs would be extremely useful, in many instances, the line between the two is blurred to the point of vanishing. Notions of health are deeply entwined with culture, beliefs about the good life, morality, and many other social norms.

A common example to raise in this context is the practice of female genital mutilation (FGM). Though it is a widely practiced cultural and religious rite of passage for girls or women in some African and Islamic societies, it is also often viewed as a threat to health (Cameron and Rawlings-Anderson, 2013). FGM has numerous negative health effects for the women and girls subjected to it, both physical and psychological. Yet, advocating against the practice necessarily pits the pursuit of health against piety and chastity, and changing beliefs about the healthfulness or harmfulness of the practice will necessarily involve challenging religious and cultural norms as well—rendering Fuller's distinction useless in this context. ${ }^{2}$

Another more subtle example of this kind of value conflict can be seen particularly clearly in the realm of mental health—especially in the WHO's 2008 mhGAP programme (Miller 2014). The mhGAP is a program developed for low-income countries to scale up services for mental, neurological, and substance use disorders (Miller 2014). While well intentioned, this program has incurred criticism due to its assumptions of "psychiatric universalism" which "extinguishes local ways of expressing and dealing with distress, replacing them with particularly Western ways" (Miller 2014, 131). Miller (2014) also cites other critics in his article, who accuse $m h G A P$ of projecting upon the world a way of being a person that is specific to contemporary Western societies (in other words, parochial biases). Indeed, it seems that Americans have been vigorously exporting their medical and psychiatric models to the rest of the world, all while failing to foresee the impact the imposition of these biases may have. As Miller $(2014,131)$ puts it, "It turns out that how a people in a culture think about mental illnesses-how they categorize and prioritize the symptoms, attempt to heal them, and set expectations for their course and outcome-influences the diseases themselves". Thus, the kind of treatment that may be appropriate for a condition like schizophrenia in the USA may fail to be therapeutic and could even be harmful in other social contexts.

For another example, Donna Matheson (2009) describes in her article, "A right to health: Medicine as Western cultural imperialism," that the very concepts of evidence-based medicine and Western medicine's emphasis on patient's rights clash with many local cultural assumptions in Angola. She notes that "Western medicine is intrinsically tied with modern Western culture, and as such is foreign to many African cultures" (Matheson 2009, 1191). While she ultimately argues that there are

\footnotetext{
${ }^{2}$ See Muyskens (2021) for a more detailed discussion of FGM and humanitarian health interventions.
} 
many positive components of the Western medical paradigm that non-Westerners would like to adopt, these cultural differences nonetheless can cause frictionespecially concerning attitudes towards finances and religion as they relate with medicine.

Importing the unchecked parochial assumptions of Western scientific medicine wholesale to communities which may hold vastly different conceptions of what it means to suffer or to be healed is not only culturally imperialistic and insensitive but also a clunky and inefficient way to go about improving global health in any measurable sense. Hence, the avoidance of these kinds of parochial impositions in the healthcare context is not merely a moral concern, but also a pragmatic one. We cannot effectively promote global health without taking culture into account.

\section{The Balancing Act: Between Cultural Sensitivity and Effective Global Health}

Thus far in this paper, I have been calling for more cultural inclusivity in the way that human rights, and the human right to health in particular, are conceived and implemented. Yet, I should also acknowledge that there have been significant efforts on the part of human rights theorists and advocates to accommodate cultural differences. Still, as the above examples demonstrate, ethnocentric assumptions have a way of creeping in all the same.

To remedy this, I will now offer a few possible routes to further minimize the risks of cultural imperialism in the context of global health. In this section, I will discuss three main strategies, (1) increased education and awareness of the cultural facets of health and medicine, (2) the cultural-translation of the universal principles articulated in international human rights and global health agreements into locally specific and familiar terms, and (3) the adoption of a patient-centered ethos for promoting global health.

\section{Education and Awareness}

The first step in solving any problem, naturally, is admitting that there is one in the first place. To that end, it is one possible strategy of mitigating imperialistic impositions in global health is to increase awareness of the cultural aspects of health and medicine-for healthcare workers, humanitarian aid workers, and policy makers alike. As it is conventionally practiced (and as Matheson 2009, and Miller 2014 have described), Western scientific medicine is not culturally neutral.

Increased cultural sensitivity training for healthcare workers and those working in global health could enable those working in these fields to reflect more deeply on the ways they may unwittingly be projecting their own cultural norms onto others. Better understandings of the value-laden nature of health and healthcare could lead to the development of more innovative and culturally neutral styles of offering effective healthcare in a variety of cultural and social contexts. 


\section{Translating Universal Principles into Local Terms}

To further combat the suspicion that human rights (and the right to health) are imposing Western values upon the rest of the world, it is important to find local analogues to the universal values embedded in human rights themselves. As Diego Silva and Jeremy Snyder $(2020,696)$ write in their contribution to The Oxford Handbook of Global Health Politics, "A demonstration that these principles [those stated in the UNESCO Declaration of Bioethics and Human Rights (UDBHR)] can be specified to, and supported in, non-Western contexts is extremely important to the legitimacy and claims of universality of this declaration". Silva and Snyder $(2020,696)$ argue that such global health declarations need to "explicitly link themselves to the cultural and religious traditions" of the groups they aim to benefit. In doing so, they echo an earlier observation made by Nie (2005) that linking the abstract principles of universal human rights specifically to non-Western cultures helps to defuse the problem of parochialism. As Nie (2005) explains, additional supporting arguments for universalism of the kind found in human rights can be found in non-Western traditions such as Confucianism and Daoism (Nie 2005, 255-256).

This process of articulating non-Western formulations of the values reflected in the various human rights declarations and global health initiatives, has found precedence in some circles of cross-cultural philosophy, as in the works of Fan Ruiping (2016), Nie Jing-Bao (2007), Daniel F.C. Tsai (2005, 2010), and Benedict Chan (2019a; b; 2014) with regard to the Confucian tradition and in Hughes (2007) from a Buddhist perspective and Sachedina (2007) for Islamic bioethics. Of course, much work remains to be done with regard to incorporating other traditions as well (i.e., African, Latin American, etc.). In addition to dispelling the impression of imperialistic agendas, cultural translation projects like these could help promote the emergence of more genuinely universal standards and increase mutual understanding through cross-cultural dialogue.

\section{Patient-Centered Ethos}

A "patient-centered" ethos for aid-in the sense of letting the recipients of health aid determine what kind of help and in what manner they would like it delivered, instead of being forced to accept whatever the providers of that aid (who are typically in the position of power in the relationship) think is best for them-would go a long way towards mitigating the risk of imperialistic oversteps. Centering the recipients' wishes and values stands in contrast with an "agent-centered" approachwhich would privilege the views and wishes of those providing healthcare aid. In theory, this should not be a revolutionary suggestion in the slightest-yet in practice, the wishes of the recipients of global health aid or humanitarian interventions are often side-lined (see Muyskens (2021) for a more detailed discussion). Respect for the wishes of the patient, even if the doctor may personally have made different choices, is an integral value in modern medical ethics. So too should it be in global health. With these three strategies, the human right to health would be better armed 
with moral credibility in the global sphere and thus could become a more effective tool against injustice.

\section{Further Complicating Factors for a Right to Health}

Claiming that there is a right to health is complicated by many things, including the fact that many things that affect health are not injustices as we usually think of them. Often, when people are ill or in pain, they are the unlucky victims of forces beyond human control—contagious or genetic diseases, accidents, natural disasters, or even their own ill-advised actions. What injustice, then, is a human right to health supposed to redress? Are the threats to health even of the kind that a political instrument like a human right could ameliorate?

Where negative health outcomes are the result of unnecessary, avoidable and unfair allocations of resources (like denying care or health resources based on race, gender, or class) this is clearly unjust - and here the language of rights may be of clear benefit. But many disparities in health are not obviously caused by such unfairness. Imagine someone who dies because they needed a kidney transplant, when there was no matching kidney available. Though this death is unfortunate, we do not think this is unjust. The necessary resources simply were not available.

Whether health conditions are thought to be the result of misfortune, the actions or inactions of other agents, or the result of the sufferer's own choices has wideranging policy implications. There are two main ways luck can show up in the realm of health, (1) "brute luck" and (2) "option luck." "Brute luck" refers to the unequal distribution of health in the natural order (i.e., we are not all born with genes that afford us the same opportunities, risks, advantages, or disadvantages), and "option luck" refers to the outcomes of conscious actions (which may still be influenced by chance) (Denier 2010).

How to deal with health disparities that are the result of luck (of either kind) is a subject of heated and continuing debate. Bioethicist Norman Daniels (2007) has argued that the luck egalitarian view results in policies that are both too narrow (denying treatment to the imprudent, like smokers contracting lung disease) and too wide (urging treatment for "brute" conditions that are unfortunate or disadvantageous but minor or frivolous, like shyness or ugliness) for a just and fair distribution of healthcare resources. But others, like Shlomi Segall (2010), have defended the view, arguing that the luck egalitarian view need not entail denying basic care to "imprudent" individuals.

This paper cannot address all of these worries with the attention they deserve, but I will give a few reasons why we should think that despite these other questions and complications, there is reason to embrace the political instrument of a human right to health. In recent years, there has been a trend in bioethics to push beyond the confines of the doctor-patient clinical relationship and toward the global. Some scholars, like George Annas (2010), have argued that this step can and should be facilitated with the language of human rights, while others (Fenton and Arras 2010; Tasioulas and Vayena 2016) are more skeptical. 
As civilizations advance and societies become ever more capable of defending human health, it becomes less justifiable not to do so (Wolff 2012). The usefulness of human rights as political instruments against injustice requires that there are political bodies to which people can address their complaints and which can act in response. ${ }^{3}$ Meaning, the emergence of political institutions capable of protecting people from a plague like the Black Death or COVID-19 carries with it the obligation to exercise those capabilities. The more control we attain over the factors which influence health, the more likely injuries to health will stem from some human actions, and thus, the likelihood that injuries to health will also be violations of the right to health also increases.

With all of the controversy about the validity of universal human rights, one may naturally ask, why engage in rights-based discourse at all? Indeed, there have been a number of criticisms of rights-based discourse as a whole. For example, some feminist scholars have criticized rights-based discourse for its presumption of a state of conflict, saying, "[i]t is only necessary to claim a right if there is a potential or actual dispute" (Wolff 2012, 21). In an ideal world, of course, rights would never need to be invoked, nor would they need institutions to uphold or defend them. But whether we like it or not, the world that we live in is one in which there is significant dispute, and therefore there is a need to keep this tool in our arsenal.

It is increasingly clear that there are many aspects of health with a global dimension-and these problems cannot properly or effectively be addressed without international and cross-cultural cooperation. The kinds of health crises that societies and individuals face from threats like famines, climate change, and pandemics (like the recent COVID-19) do not stop at borders. As moral agents, we have reason to mitigate the brute luck of others, regardless of national boundaries. We need not think that the ill health of others must be the result of persecution or deliberate discrimination before it is a matter of concern for global justice. The fact that others suffer through no fault of their own and the presence of a feasible alternative is sufficient.

Given what is at stake, we have abundant reason to hold on to any tools in the arsenal that may enable us to make progress in global health and justice. Despite their imperfections and complications, the language of human rights remains a powerful tool to address health disparities when they are the result of injustice and also a powerful motivator for global action in the face of transnational threats to health.

\section{Conclusion}

Health is vital for so many activities which give meaning and pleasure to human lives. As the ancient Greek philosopher Herophilus once said, "When health is absent, wisdom cannot reveal itself, art cannot manifest, strength cannot fight, wealth becomes useless, and intelligence cannot be applied." Despite the difficulties

\footnotetext{
${ }^{3}$ Elsewhere, I have argued that, where the usual political institutions have failed or are absent, the duty to uphold the right to health ought to diffuse to the next most capable body-which may be an international non-governmental organization (INGO) or other kind of charity (Muyskens 2021). Such institutions are usually apolitical, but this distinction has become blurred in recent years. In these cases, even if the duty bearers of human rights are not confined to states alone, their nature as political instruments stands.
} 
of navigating cultural differences in this context, such a vital component of human life deserves the protection that the instruments of human rights can offer to defend it from unjust infringements. This paper has hardly solved every controversy surrounding human rights, but the mission here has never been to solve them all. The human right to health can and ought to be a weapon against the structural violence that forces so many of the world's poorest people into illness and premature death and a political instrument to help us all combat global health crises as they inevitably arise. Empowering people in this way is the opposite of imperialism.

Acknowledgements I would like to thank Jonathan Wolff and Andres Luco for their extensive feedback on earlier drafts.

Data Availability Not applicable.

\section{Declarations}

Conflict of Interest The author states that there is no conflict of interest.

\section{References}

Annas, George J. 2010. Human Rights and American Bioethics: Resistance is Futile. Cambridge Quarterly of Healthcare Ethics 19 (1): 133. https://doi.org/10.1017/S0963180109990338.

Beitz, Charles R. 2009. The Idea of Human Rights. Oxford: Oxford University Press.

Cameron, Joan and Karen Rawlings-Anderson. 2013. Genital Mutilation: Human Rights and Cultural Imperialism. British Journal of Midwifery 9 (4): 231-236. https://doi.org/10.12968/bjom.2001.9.4. 8903.

Chan, Benedict S.B. 2014. A Human rights debate on physical security, political liberty, and the Confucian tradition. Dao: A Comparative Journal of Philosophy 13 (4): 567-588. https://doi.org/10.1007/ s11712-014-9403-0.

Chan, Benedict S.B. 2019a. A preliminary consequential evaluation of the roles of cultures in human rights debates. Filosofia Theoretica: Journal of African Philosophy, Culture and Religions 8 (1): 163-182. https://doi.org/10.4314/ft.v8i1.11.

Chan, Benedict S.B. 2019b. Enhanced Interrogation, Consequential Evaluation, and Human Rights to Health. Journal of Bioethical Inquiry 16 (3): 455-462. https://doi.org/10.1007/s11673-019-09927-z.

Cruft, Rowan, S. Matthew Liao, and Massimo Renzo, eds. 2015. Philosophical Foundations of Human Rights. Oxford: Oxford University Press. https://doi.org/10.1093/acprof:oso/9780199688623.001. 0001.

Dallmayr, Fred Reinhard. 2002. 'Asian Values' and Global Human Rights. Philosophy East and West 52 (2): 173-189. https://doi.org/10.1353/pew.2002.0025.

Daniels, Norman. 2007. Just Health: Meeting Health Needs Fairly. New York, NY: University Press. https://doi.org/10.1017/CBO9780511809514.

Denier, Yvonne. 2010. From Brute Luck to Option Luck? On Genetics, Justice, and Moral Responsibility in Reproduction. Journal of Medicine and Philosophy 35 (2): 101-129. https://doi.org/10.1353/pew. 2002.0025.

Engle, Karen. 2001. From Skepticism to Embrace: Human Rights and the American Anthropological Association from 1947-1999. Human Rights Quarterly 23 (3): 536-559. https://doi.org/10.1353/ hrq.2001.0034.

Fan, Ruiping. 2016. Nonegalitarian Social Responsibility for Health: A Confucian Perspective on Article 14 of the UNESCO Declaration on Bioethics and Human Rights. Kennedy Institute of Ethics Journal 26 (2): 195-218. https://doi.org/10.1353/ken.2016.0011. 
Fenton, Elizabeth, and John D. Arras. 2010. Bioethics and Human Rights: Curb Your Enthusiasm. Cambridge Quarterly of Healthcare Ethics 19 (1): 127. https://doi.org/10.1017/S0963180109990326.

Fuller, Lisa. 2012. International NGO Health Programs in a Non-Ideal World: Imperialism, Respect, and Procedural Justice. In Global Justice and Bioethics. Ed. Joseph Millum and Ezekiel J. Emanuel. New York, NY: Oxford University Press.

Gawlikowski, Krzysztof. 2000. Asian Values' and Western Universalism. Dialogue and Universalism 10 (1/2): 183-187.

Goodman, Timothy. 2005. Is There a Right to Health? Journal of Medicine and Philosophy 30 (6): 643662. https://doi.org/10.1080/03605310500421413

Griffin, James. 2008. On Human Rights. Oxford: Oxford University Press.

Hughes, James. 2007. Buddhist Bioethics. In Principles of Health Care Ethics. Eds Richard E. Ashcroft, Angus Dawson, Heather Draper and John R. McMillan. Chichester: John Wiley \& Sons.

Kramer, Matthew H. 2013. Some Doubts About Alternatives to The Interest Theory of Rights. Ethics 123 (2): 245-263. https://doi.org/10.1086/668705.

Li, Xiaorang. 1999. 'Asian Values' and the Universality of Human Rights. Business and Society Review 102 (1): 81-87. https://doi.org/10.1111/0045-3609.00028.

Matheson, Donna. 2009. A right to health: Medicine as Western cultural imperialism. Disability and Rehabilitation 31 (14): 1191-1204. https://doi.org/10.1080/09638280902773794.

Miller, Gavin. 2014. Is the Agenda for Global Mental Health a Form of Cultural Imperialism? Medical Humanities 40 (2): 131-134. https://doi.org/10.1136/medhum-2013-010471.

Muyskens, Kathryn. 2021. Intervening on Behalf of the Human Right to Health: Who, When, and How? Human Rights Review 22 (2): 173-191. https://doi.org/10.1007/s12142-021-00620-6.

Nie, Jing-Bao. 2005. Cultural Values Embodying Universal Norms: A Critique of a Popular Assumption About Cultures and Human rights. Developing World Bioethics 5(3): 251-257. https://doi.org/10. 1111/j.1471-8847.2005.00123.x.

Nie, Jing-Bao. 2007. The Specious Idea of an Asian Bioethics: Beyond Dichotomizing East and West. In Principles of Health Care Ethics. Eds Richard E. Ashcroft, Angus Dawson, Heather Draper and John R. McMillan. Chichester: John Wiley \& Sons.

Nozick, Robert. 1974. Anarchy, State, and Utopia. New York, NY: Basic Books.

Pogge, Thomas W. 2002. Responsibilities for Poverty Related Ill-Health. Ethics \& International Affairs 16 (2): 71-79. https://doi.org/10.1111/j.1747-7093.2002.tb00398.x.

Raz, Joseph. 2010. Human Rights Without Foundations. In The Philosophy of International Law. Eds Samantha Besson, and John Tasioulas. Oxford: Oxford University Press.

Sachedina, Abdulaziz. 2007. The Search for Islamic Bioethics Principles. In Principles of Health Care Ethics. Eds Richard E. Ashcroft, Angus Dawson, Heather Draper and John R. McMillan. Chichester: John Wiley \& Sons.

Segall, Shlomi. 2010. Is Health (Really) Special? Health Policy Between Rawlsian and Luck Egalitarian Justice. Journal of Applied Philosophy 27 (4): 344-358. https://doi.org/10.1111/j.1468-5930.2010. 00499.x.

Shafer-Landau, Russ. 2018. Ethical Relativism. In The Fundamentals of Ethics. New York, NY: Oxford University Press.

Silva, Diego S. and Jeremy Snyder. 2020. Politics of Global Bioethical Frameworks. In The Oxford Handbook of Global Health Politics. Eds Colin McInnes, Kelley Lee, and Jeremy Youde. Oxford: Oxford University Press.

Sreenivasan, Gopal. 2012. A Human Right to Health? Some Inconclusive Scepticism. Proceedings of the Aristotelian Society Supplementary 86 (1): 239-265. https://doi.org/10.1111/j.1467-8349.2012. 00216.x.

Talbott, William. 2005. Which Rights Should be Universal? Oxford: Oxford University Press.

Tasioulas, John. 2007. The Moral Reality of Human Rights. In Freedom From Poverty as a Human Right: Who Owes What to the Very Poor? Ed. Thomas Pogge. New York, NY: Oxford University Press.

Tasioulas, John. 2009. Are Human Rights Essentially Triggers for Intervention? Philosophy Compass 4 (6): 938-950. https://doi.org/10.1111/j.1747-9991.2009.00246.x.

Tasioulas, John. 2013. Human Rights, Legitimacy and International Law. American Journal of Jurisprudence 58 (1): 1-25. https://doi.org/10.1093/ajj/aut001.

Tasioulas, John, and Effy Vayena. 2016. The Place of Human Rights and the Common Good in Global Health Policy. Theoretical Medicine and Bioethics 37 (4): 365-382. https://doi.org/10.1007/ s11017-016-9372-x. 
Tsai, Daniel F.C. 2005. The Bioethical Principles and Confucius' Moral Philosophy. Journal of Medical Ethics 31 (3): 159-163. https://doi.org/10.1136/jme.2002.002113.

Tsai, Daniel F.C. 2010. Reflecting on the Nature of Confucian Ethics. American Journal of Bioethics 10 (4): 84-86. https://doi.org/10.1080/15265161003686498.

Wolff, Jonathan. 2012. The Human Right to Health. New York, NY: W.W. Norton.

Publisher's note Springer Nature remains neutral with regard to jurisdictional claims in published maps and institutional affiliations. 